\title{
Cancer Genetics Services in Europe
}

\author{
S. Hodgson ${ }^{1, \#, ~ B . ~ M i l n e r ~}{ }^{2}$, I. Brown ${ }^{2}$, \\ G. Bevilacqua ${ }^{3}$, J. Chang-Claude ${ }^{4}$, \\ D. Eccles ${ }^{5}$, G. Evans ${ }^{6}$, H. Gregory ${ }^{2}$, \\ P. Møller ${ }^{7}$, P. Morrison ${ }^{8}$, M. Steel ${ }^{9}$, \\ D. Stoppa-Lyonnet ${ }^{10}$, H. Vasen ${ }^{11}$ \\ and N. Haites ${ }^{2}$
}

${ }^{1}$ Division of Medical and Molecular Genetics, Guy's Hospital, London Bridge, London SE1 9RT, UK

${ }^{2}$ Medical Genetics, Department of Medicine and Therapeutics, University of Aberdeen, Foresterhill, Aberdeen AB25 2ZD, UK

${ }^{3}$ Institute of Pathology, University of Pisa, Via Roma, 57, Pisa, Italy

${ }^{4}$ Division of Epidemiology, German Cancer Research Centre, Im Neuenheimer Feld 280, D-69120 Heidelberg 1, Germany ${ }^{5}$ CRC Genetic Epidemiology Research Group, Wessex Regional Genetics Service, Southampton SO9 4HA, UK

${ }^{6}$ Medical Genetics, St. Mary's Hospital, Hathersage Road, Manchester M13 OJH, UK

${ }^{7}$ The Norwegian Radium Hospital, N-0310

Oslo, Norway

${ }^{8}$ Department of Medical Genetics, City Hospital, Belfast, UK

${ }^{9}$ School of Biological and Medical Sciences, Bute Medical Building, St Andrews, Fife KY16 9TS, UK

${ }^{10}$ Unité de Génétique Oncologique, Institut Curie - Section Medicale, 26 rue d'Ulm, 75231 Paris cedex 05, France

${ }^{11}$ Foundation for the Detection of Hereditary

Tumours, clo University Hospital,

\footnotetext{
\# Correspondence: S. Hodgson, Division of Medical and Molecular Genetics, Guy's Hospital, London Bridge, London SE1 9RT, UK
}

Rijnsburgerweg 10, 2333 AA Leiden, The Netherlands

It has long been recognised that some very rare forms of cancer predisposition, such as retinoblastoma, are caused by inherited gene mutations [7]. It is only within the last decade or so, however, that rapid progress has been made in understanding the role that inherited mutations also play in determining a proportion of the more common cancers, including breast, colorectal and ovarian cancer $[1,2,3,4,6,8,9,10]$. Although there is still uncertainty about the precise contribution of inherited predisposition genes to the incidence of these cancers, the available evidence suggests that breast, colorectal and ovarian cancer have a number of common genetic features:

- A small proportion of these cancers (about $5 \%$ ) are caused by inherited gene mutations which, though comparatively rare, confer very high lifetime risks of developing cancer. In some cases these lifetime risks may be as high as $80 \%$.

- Cancers caused by these high-penetrance genes are likely to occur at an earlier age than sporadic cancers, and $15-20 \%$ of the cancers diagnosed in people under the age of 50 may be accounted for by these genetic mutations.

- Carriers of known genetic mutations which confer high lifetime risks of developing breast, colorectal or ovarian cancer are also at a somewhat increased risk of developing certain other forms of cancer.

- A further 10-20\% of breast, colorectal and ovarian cancers may be caused by other inherited predisposition genes which are less penetrant but which confer some increased risk (more than 3 times the general population risk). These "medium risk" genes are only beginning to be identified. 
- Familial clustering of the more common cancers may also be influenced by environmental and lifestyle factors as well as by chance.

\section{CANCER SERVICES IN EUROPE}

Individual countries in Europe offer a wide range of types of health services to their population. This variation reflects differences in the balance between nationally and privatelyfunded services, in the wealth and size of the countries, in the acceptance and establishment of genetic services, and in the demands made upon the services by the population and their perceived needs. While many services have developed as a result of evidence from the medical literature, others have been developed as a result of patient pressure and medical practitioner interest, often modified to allow a country to offer that which is affordable.

Hence, when it comes to cancer services across a range of countries in Europe, it is not surprising to find that there is wide variation in the basic services available and the equity with which they are offered. From a survey of 89 centres in 34 countries it is possible to document the range of services currently available in Europe (Table 1; Figures 1-3). For population breast screening, the majority of countries offer breast screening by mammography from 50 years of age. In most of these countries this occurs every two years. A few countries start screening from an earlier age (between 30 and 50 years of age), and offer mammography every one to five years. As a consequence of this wide variation, it is not surprising to find that services for individuals perceived to be at increased risk on the basis of their family history also cover a wide spectrum and involve a range of different professional disciplines.

\section{SERVICES FOR CANCER GENETICS}

Cancer Genetics is a new field, and the organisation of services in this area may be

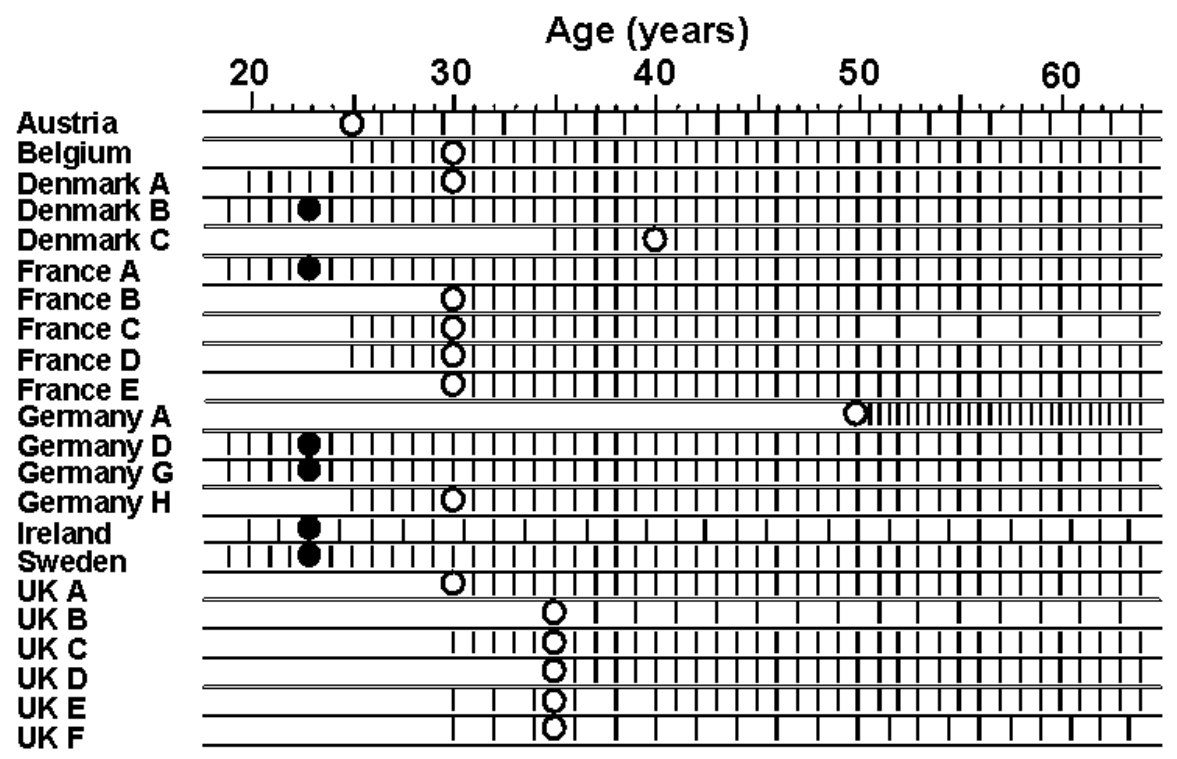

Fig. 1. Breast Screening by Mammography: High Risk Women: EC Countries. Open circles represent screening from age $\mathrm{x}$, or $\mathrm{n}$ years younger than youngest affected relative. Closed circles represent screening from $\mathrm{n}$ years younger than youngest affected relative, age not specified. Solid bars represent each screening event. 


\section{Age (years)}

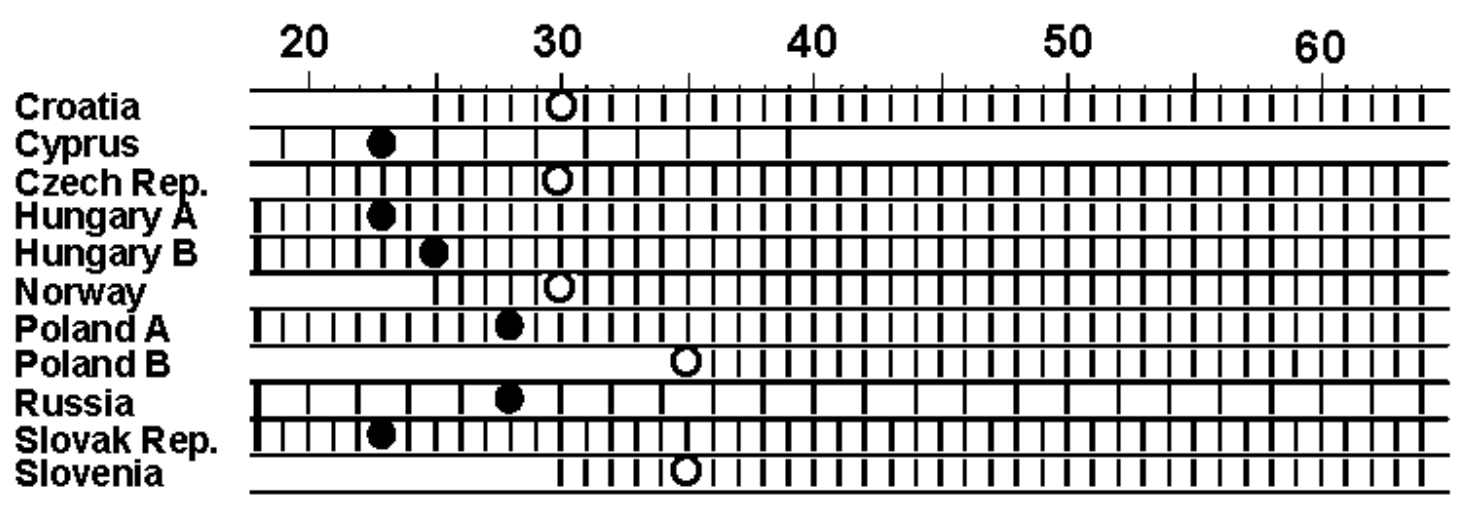

Fig. 2. Breast Screening by Mammography: High Risk Women: Non-EC Countries. Open circles represent screening from age $\mathrm{x}$, or $\mathrm{n}$ years younger than youngest affected relative. Closed circles represent screening from $\mathrm{n}$ years younger than youngest affected relative, age not specified. Solid bars represent each screening event.

\section{$\begin{array}{cc}\text { Centre } & \text { FCR } \\ \text { Popn. } & \text { Near } \\ \text { (Millions) } & \end{array}$}

\begin{tabular}{|c|c|c|c|}
\hline Austria & 2.0 & 162 & N/A \\
\hline Czech Republic & 1.0 & 192 & (n) \\
\hline Denmark A & 1.6 & 72 & ( \\
\hline Denmark C & 0.5 & 158 & 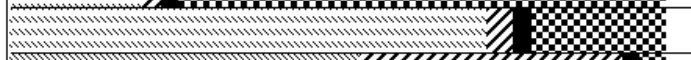 \\
\hline France A & 1.3 & 80 & 8 \\
\hline France B & 2.0 & 300 & 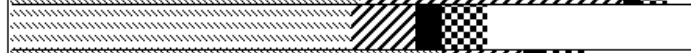 \\
\hline France C & N/A & 266 & 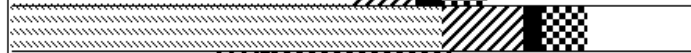 \\
\hline France D & 2.0 & 236 & /// $\& \mathcal{Q} \& \mathcal{Q}$ \\
\hline France $\mathrm{E}$ & 1.0 & 53 & 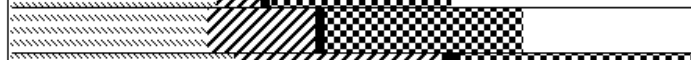 \\
\hline Germany A & N/A & 86 & , / \\
\hline Germany B & N/A & 12 & m \\
\hline Germany C & N/A & 22 & \\
\hline Germany D & 1.0 & 35 & \\
\hline Germany F & 2.0 & 45 & \\
\hline \multirow[t]{2}{*}{ Germany $G$} & N/A & 87 & , $\$ 2 \%$ \\
\hline & & & \\
\hline
\end{tabular}

Fig. 3a. Referral Breakdown. FCR = Familial Cancer Referrals; $\mathbf{W}=$ Breast Only; $\boldsymbol{Z}=$ Breast/Ovarian; = Including Male Breast $\mathbf{M}$ = FAP / HNPCC; $\square$ = Other. 


Hungary A
Ireland
Italy
Lithuania
Norway
Poland B
Russia
Slovenia
Sweden
Switzerland
UK A
UK B
UK C
UK D
UK E
UK F
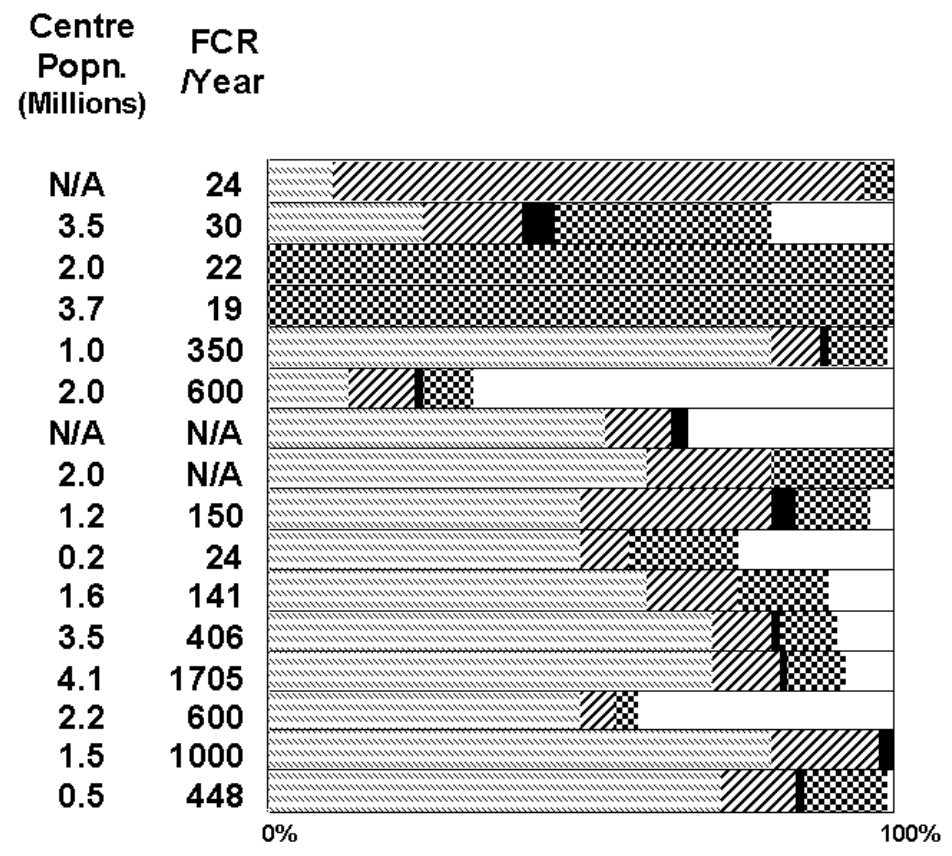

Fig. 3b. Referral Breakdown. FCR = Familial Cancer Referrals; $\mathbf{W}=$ Breast Only; $Z \mathbf{Z}=$ Breast/Ovarian; = Including Male Breast; $\boldsymbol{\theta}=$ = FAP / HNPCC; $\square=$ Other.

initiated by Clinical Genetic Services or through Oncology, Surgery and other departments, where individuals with a special interest arrange to see individuals with a family history of cancer. Many are currently being provided as part of research projects. Government Health Departments are reluctant to provide funding for such services until evidence-based audit can ensure their cost-effectiveness; this is not yet available. The acceptance and recognition of genetics as a speciality is important for service development.

The growth of cancer genetics services will depend upon the infrastructure and network of Genetics Centres and other clinical services in the country including primary care. Good communication between different Centres promotes the development of compatible and coordinated services which can be evaluated over time. The level of public awareness of genetic issues is reflected in demand for this service. Other factors influencing the level of services include the tradition of screening (e.g. thalassaemia in Mediterranean countries), the degree of development of registers for genetic conditions and cancer, and the acceptance of the role of genetic counsellors.

In the majority of countries in Western Europe, services for familial breast cancer are provided with funding from the Government, but even in that situation, this type of service is only available to a percentage of the population. A smaller number of countries have services funded by both the Government and from Research funds, and in those countries where the only funding for service is from research or Health Insurance and private practice, the number of individuals for whom this is available will be a small percentage of those at risk.

\section{POSITION IN THE UK}

In the UK, Regional Genetics Centres have been established for many years, and most specialised genetic counselling for cancer susceptibility is organised from the Genetic 


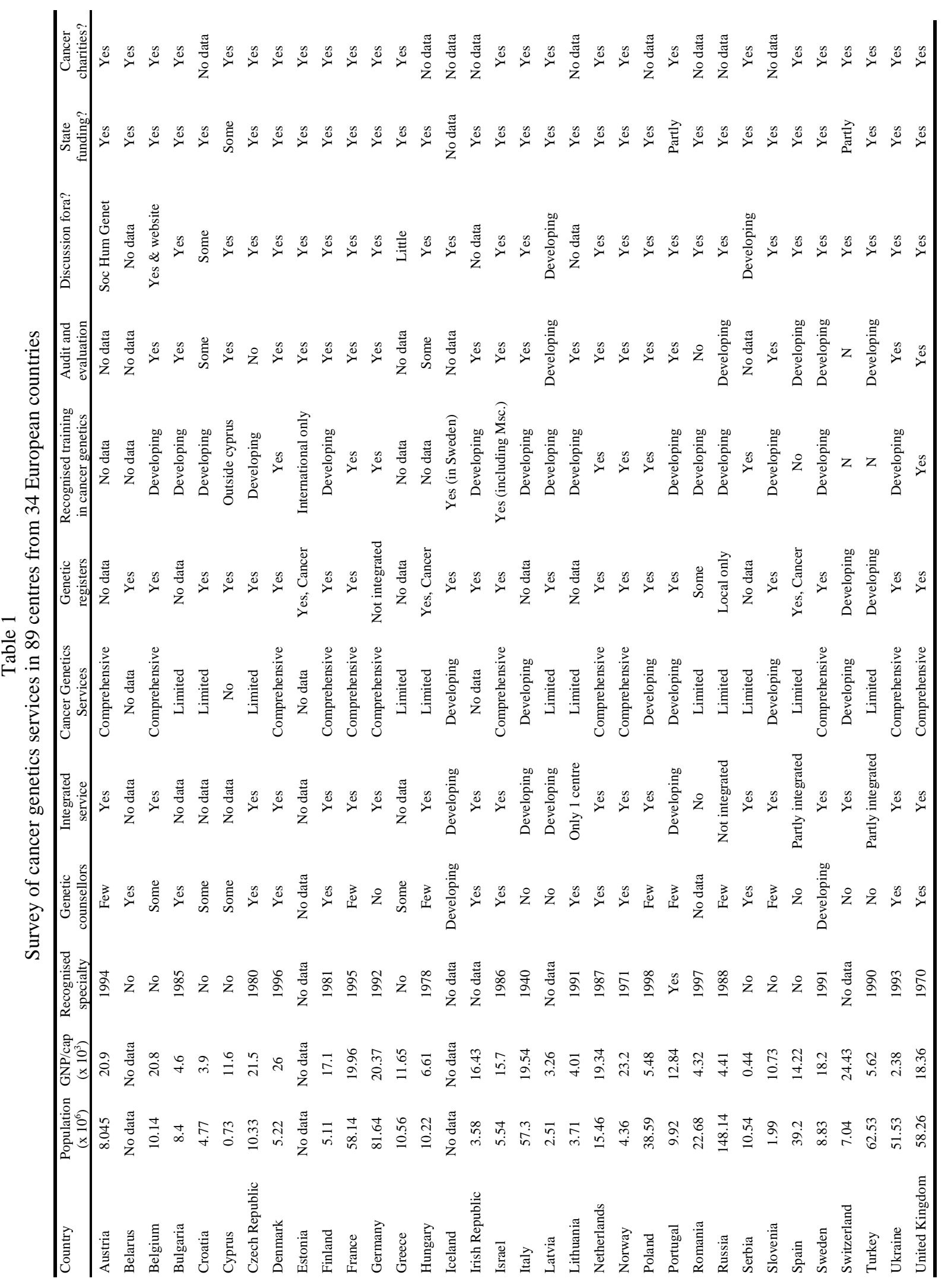


Centres. However, there is increasing awareness that education and referral guidelines for primary care physicians is important. This would allow a collaborative relationship to be developed with primary health care services, helping them to act as gatekeepers for the prioritisation of referrals for genetics services. A second "layer" of service provision is envisaged in cancer units where individuals at moderately increased risk can be managed. This would ensure that only high-risk individuals, in whose families it is probable that a genetic cancer predisposition is segregating, are seen in genetics centres.

The most appropriate structure for such a service is likely to be:

1. A "gatekeeper" function of primary care, with guidelines and educational material provided by the genetics service, to ascertain individuals with a positive family history of cancer and refer individuals on to either 2. or 3.

2. A network of "moderate-risk" clinics, possibly multidisciplinary, and perhaps based in Cancer Units and other clinics (oncology; breast surgical). These would be manned by trained genetic counsellors (who may be doctors, nurses or genetic associates), with oncologists and other relevant clinicians (surgeons; gastroenterologists). Counselling and risk assessment would be provided, appropriate clinical surveillance protocols instituted and audited, and referrals arranged for high-risk individuals to the local genetics centre.

3. The genetics service, which should concentrate on high-risk families, staffed by clinical geneticists and genetic counsellors. These would provide genetic counselling and predictive testing, backed up by appropriate molecular expertise and psychological support as necessary. There should be facilities for the long-term audit of surveillance protocols. This would be most appropriately monitored centrally, within the genetics centre.

It is apparent that because of its large scale, such a service must rely heavily on genetic counsellors and clinicians with an interest in a specialised area of genetics rather than geneticists alone. There should be a high degree of coordination and collaboration between disciplines, particularly as many countries will initiate cancer genetics services from oncology or other (non-genetic) clinical services.

In the UK, genetic counselling is currently offered by consultant clinical geneticists supported by specialist registrars and genetic counsellors. The genetic counsellors are usually nurses who have received training (often "in house") in genetics. However, there are increasing numbers of graduates without a nursing background who have attended a course in genetic counselling. These genetic associates would also potentially have an important role to play in delivering the cancer genetics service. The career structure of these individuals is still being developed. Genetic counsellors are likely to play an important role in overseeing the "gatekeeper" functions of primary care.

MSc. courses in genetic counselling are being developed. In the UK, one two-year course is available at Manchester University (since 1992), and modules in Cancer Genetics are now available in some other UK centres as part of genetics or nursing curricula. A working party was convened in 1994 by the Genetic Nurses and Social Workers Association in response to the debate about the role of nurses in the activities of a Regional Genetic Centre. The Association of Genetic Nurses and Counsellors (AGNC) has developed guidelines for training, assessment of competency, and the most appropriate role and responsibilities of genetic counsellors [11,12]. They are also addressing the career progression for such counsellors. This has coincided with the decision to produce educational guidelines and the normalisation of requirements for specialist nurse practice in all areas of health care (UK Central Council, the statutory regulatory body for nursing practice in the UK).

\section{POSITION THROUGHOUT THE REST OF EUROPE}

Throughout the remainder of Europe, the recognition and provision of genetics services varies widely, influenced by historical, geographic, political and economic factors. A BIOMED 1 survey examined services in 
European countries [5]. Multidisciplinary Regional Genetics Centres are only well established in the UK, Netherlands and Belgium, and genetics is only recognised as an official speciality in 20 of 31 European countries [5]. The highest reported proportions of geneticallytrained clinicians are in Belgium, Bulgaria, Cyprus, the Czech Republic, Hungary, Finland, the Netherlands, Germany, Greece, Israel and the Ukraine; the UK has relatively few, despite being one of the first countries in which genetics was recognised as a speciality.

The presence of cancer registries and genetics registers, particularly those recording data on cancer-predisposing syndromes, provides a positive impetus for the development and coordination of cancer services. Such registers are well developed in the UK, Belgium, Finland, the Netherlands, Norway, Poland, Sweden and Denmark. Others are being developed in Cyprus, Hungary, Latvia, Romania, Slovenia, Switzerland and the Ukraine. Several European countries have developed national networks for standardisation of cancer genetics services. These include the Cancer Family Study Group in the UK, the Danish Breast Cancer Collaborative Group, and the Netherlands National Registry of Hereditary Breast Cancer Families. In France, "Centres Against Cancer" (CLCC) are supported by a French charity, the League Against Cancer, which is part of the network known as the Genetics and Cancer Group from the FNCLCC (Federation Nationale des Centres de Lutte Contre le Cancer). This group fosters nationwide collaboration in the conduct of the management of genetic cancer susceptibility, including oncologists, radiotherapists, surgeons and geneticists involved in the field, and has initiated the concept of "oncogeneticists". Other specialist organisations which encourage international collaboration in research and management of hereditary cancers include EUROFAP and ICG-HNPCC (Colorectal cancer susceptibility).

There follow some details about cancer genetics services in selected countries in Europe; further information is tabulated and shown graphically (Table 1, Figures 1-3).
In Denmark, clinical genetics was only recognised as a medical speciality very recently (1996), so that the responsibilities and training of doctors who offer genetic counselling have not yet been clearly delineated. Specialist courses in cancer genetics are available for doctors but not yet for associates, and patient support groups are not yet well developed. However, Denmark runs a cancer genetics registry for individuals with Familial Adenomatous Polyposis (FAP) and colorectal cancer, and cancer genetics services are becoming well-developed, with the acceptance of a role for nurses in selecting highrisk individuals from peripheral units.

In the Netherlands there is a well-developed network of Regional Clinical Genetics centres and family cancer clinics in Dutch medical academic centres. These offer genetic counselling and DNA diagnosis. There is an independent National Registry for families with hereditary cancer (established in 1993) which is managed by the Foundation for the Detection of Hereditary Tumours (supported by the Ministry of Health). The aims of the National Registry are: 1. to promote surveillance in families with hereditary cancer; 2 . to guarantee the continuity of surveillance; and 3. to promote research. Referrals to the clinical genetics centres for genetic counselling are arranged as appropriate. These activities are perceived as complementary.

In France, a network of cancer genetics clinics has developed, initiated in 1986 by a group with research interests in hereditary breast and ovarian cancer (HBOC) situated in Lyon. The Lyon clinical service was initially focused on obtaining a clinical resource for research. However, the need to provide a clinical service for the families ascertained led on to the development of a network of clinics in the Centres Against Cancer (CLCC) referred to above. Nurses and genetic counsellors do not yet have a significant role in service delivery.

In Belgium all genetic counselling is offered by doctors, some of whom are oncologists with training in genetics. There are some researchbased genetic counsellors (nurses, social workers, psychologists) but there is no formalised training or role for these. 
In Germany, counselling is exclusively offered by doctors. There is a multicentre interdisciplinary network for the management of hereditary breast cancer, established in 1995 under the auspices of the Ministry of Health Cancer Programme, and several task forces were set up to promote collaboration. This advised the Deutsche Krebshilfe on its National BRCA1 research funding scheme, and in January 1997 ten centres, located in medical schools throughout Germany, were funded by a DM 10 million research grant to develop a comprehensive service structure to include the counselling and molecular aspects of this work, within three years. There are currently few formal genetics centres, but several centres offer molecular testing and counselling for specific genetic conditions such as FAP or MEN. Selfhelp groups exist and there is a newsletter for FAP families.

In Italy there are several relatively autonomous regions which are currently looking for funding to set up a network of genetics centres; this application is being co-ordinated in Milan (National Cancer Institute) with a five-year research grant; no genetics nurses are employed within the existing (research-based) services.

Clearly to a certain extent the ability to offer a population-based service is related to the wealth of the country as well as to the established nature of medical genetics in medical practice (Table 1). Each country and sometimes different centres in the same country will offer different screening protocols for women at an increased risk of breast and other cancers. For breast cancer it can be seen in Figures 1 and 2 that the mammographic screening offered to women at twice the population risk varies widely and until further evidence is available to inform such procedures this will continue to be the case.

The types of family histories selected for referral to different centres can also be seen to vary. This depends upon the interests of individuals running the Clinic. Where referrals for all types of history are accepted, a history of breast cancer is currently the most common reason for referral (Figure 3).
Audit of cancer genetics services is important, as the services develop, and audit is welldeveloped in Belgium, Denmark, Finland, France, Germany, Israel, Italy, the Netherlands, Norway, Sweden, Poland and the UK (Table 1).

\section{ROLE OF GENETIC COUNSELLORS}

Currently the employment of genetic counsellors within the cancer genetic services varies a great deal between countries. The UK has several genetic counsellors attached to each Regional Genetics centre. Their roles include interviewing probands, constructing pedigrees, confirming diagnoses and stratifying risk estimates. Many will act as the primary genetic counsellor for cancer genetics. They maintain screening protocols, organise clinics, liase with other health professionals, and may undertake home visits. They may obtain samples for research studies, and co-ordinate such research. They are also becoming involved in the provision of educational material for patients and health professionals, and may help in the development of patient support groups. In some Centres in the UK, they have considerable autonomy in delivering genetic counselling for specific cancer genetic referrals within a structured framework supervised by the clinical genetics departments. The Cancer Family Study Group and the ICRF cancer genetic nurse support group help maintain uniformity of standards.

The participation of genetic counsellors in the provision of such services in other European countries is much less established, and in most cases any co-workers that are employed are involved in research or organisational activities.

There are over 800 genetics associates in 25 European countries, with highest rates in the UK, Finland, Denmark, Israel and the Netherlands. Greece is developing an MSc. course for genetic counsellors. Most countries, however, do not make use of genetic counsellors in service delivery to a significant degree, and there are none in France, Germany, Latvia, Russia, Slovenia, Spain or Turkey, and few in Croatia, 
Sweden, Italy or Norway. In these countries there is currently no formal training in genetics for nurses.

Integral to the development of a broad-based cancer genetics service is the provision of education at several levels - for the public, primary care health professionals, and hospital clinicians.

Education of the public in issues of cancer genetics is expanding, as part of the general education for genetic issues, with the provision of media coverage, museum exhibitions (such as the specialist "Gene Dome" in Newcastle, UK, and the Millennium exhibition at the Science Museum in London) (Table 2). There are also proliferating world-wide web sites, for example the Human Genome Information site, which can be accessed at http://www.ornl.gov/ TechResources/Human_Genome/home.html (see also Table 3).

The Cancer Family Study Group in the UK is an example of a forum for health care professionals, facilitating discussion of new developments in cancer genetics, and management issues. Patient support groups are beginning to be developed for cancer genetics, either by cancer charities or genetics groups such as the Genetic Interest Group (GIG) and Cancer Link. A new body, the Public Health Genetics Unit (PHGU) was set up in 1997 to provide education in genetics and a link between academic research, clinical practice and the development of NHS policy, and to promote dialogue within the NHS between geneticists, physicians, public health and primary care professionals in relation to genetic issues.

Cancer genetics courses are beginning to be offered by specialised centres such as Sestri Levante (Italy), and the Cancer Genetics module at the Royal Marsden Hospital (London). In the UK, modules for cancer genetics are being introduced for nurses (ENB), and cancer genetics is taught as part of the MSc. courses in genetics and genetic counselling in Manchester, Cardiff and London. In Israel, there is a course for genetic counsellors at the Hebrew University in

Table 2

Educational material on cancer genetics (examples from the UK in particular)

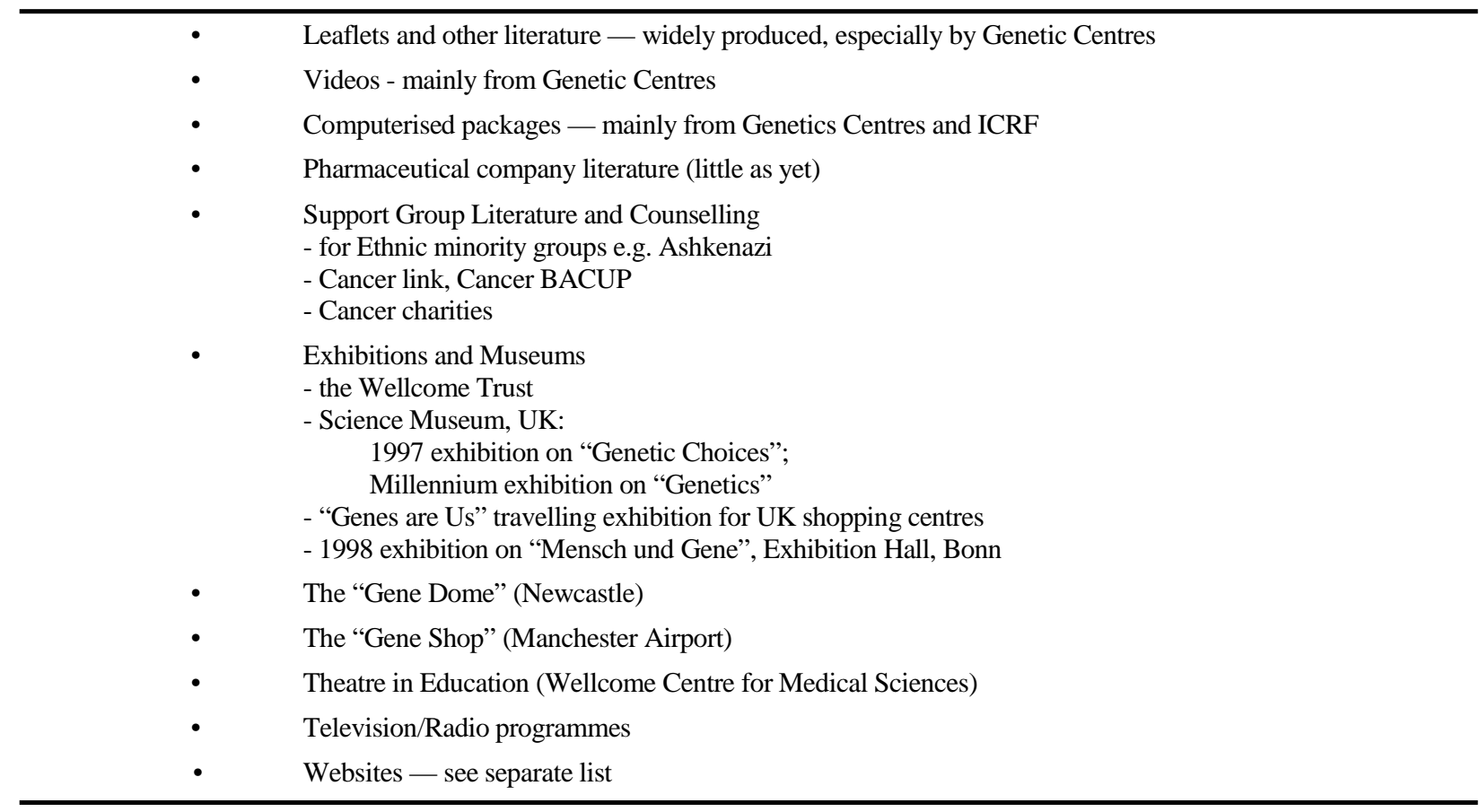


Table 3

Sites on the Worldwide Web

The Worldwide Web has several sites which address cancer genetics issues, including:

- What is Genetic Screening? (BIOSIS)

http://www.scicomm.org.uk/biosis/human/whatis/html

- Understanding Gene Testing (European Initiative for Biotechnology Education; resources for teaching aimed at 16-19y old students)

http://134.225.167.114:8001/EIBE/preview/html

- Advisory Committee on Genetic Testing Draft Code of Practice (BIOSIS) http://www.scicomm.org.uk/biosis/acgt/ACGT2/html

- "The Gene Letter" (internet-based newsletter, aiming to educate consumers and professionals about emerging medical, ethical, legal and policy dilemmas in this area. Established by the Shriver Center with a grant from the US Department of Energy/ELSI programme). Further discussions about this appear on:

http://www.geneletter.org

- Cancer Facts (National Cancer Institute) supplies information for cancer patients, their families, and the public, and backs this up with a telephone advice service.

w.graylab.ac.uk/cancernet/600349.html

cancerweb@www.graylab.ac.uk

- As part of the Cancer Genome Anatomy Project, funded by the NCI, Al Gore recently unveiled a website with the aim of having "all the pieces together in the same place".

Jerusalem, associated with the medical school at Hadassah, Ein Karem. Entry criteria include a first degree in Biology with a high average mark. The course lasts 3 years ( 30 credits per year), and after graduation the student is required to work under supervision in a genetic clinic for recognition by the Ministry of Health.

Computer packages to help primary care physicians assess risks from pedigree data are being developed and evaluated in countries such as the UK. Their implementation would require general agreement that this was beneficial, and probably a genetic counsellor trained in cancer genetics, based in primary care, would be required to facilitate this. Several models of using such methods for prioritising referrals are currently being assessed in the UK.

As evidence is obtained to demonstrate the value of a Cancer Genetics service in reducing morbidity and mortality from cancer, it is hoped that this service will be developed with the backing of the Health Ministries in all European countries, and our Demonstration Project hopes to aid this process.

\section{References}

[1] Aaltonen, L.A., Peltomaki, P., Leach, F.S., et al. Clues to the pathogenesis of familial colorectal cancer. Science 260, (1993) 812-816.

[2] Easton, D.F., Bishop, D.T., Ford, D., Crockford, G.P. and the Breast Cancer Linkage Consortium. Genetic linkage analysis in familial breast and ovarian cancer: results from 214 families. Am. J. Hum. Genet. 52, (1993) 678-701.

[3] Groden, J., Thliveris, A., Samowitz, W. et al. Identification and characterization of the familial adenomatous polyposis coli gene. Cell 66, (1991) 589-600.

[4] Hall, J.M., Lee, M.K., Newman, B., et al. Linkage of early-onset familial breastcancer to chromosome 17q21. Science 250, (1990) 1684-1689.

[5] Harris, R. Medical Genetic Services in 31 countries: an overview. Eur. J. Hum. Genet. 5(Suppl 2), (1997) 3-21.

[6] Kinzler, K.W., Nilbert, M.C., Su, L.-K. et al. Identification of FAP locus genes from chromosome 5q21. Science 253, (1991) 661-665.

[7] Knudson, A.G., Jr. Mutation and cancer: statistical study of retinoblastoma. Proc. Nat. Acad. Sci. 68, (1971) 820-823. 
[8] Lynch H.T., Albano W., Black L. et al. Familial excess of cancer of the ovary and other anatomic sites. J. Am. Med. Assoc. 245, (1981) 261-264.

[9] Miki, Y., Swensen, J., Shattuck-Eidens, D. et al. A strong candidate for the breast and ovarian cancer susceptibility gene BRCA1. Science 266, (1994) 66-71.

[10] Peltomaki, P., Aaltonen, L.A., Sistonen, P. et al. Genetic mapping of a locus predisposing to human colorectal cancer. Science 260, (1993) 810-812.

[11] Skirton, H., Barnes, C., Curtis, G. et al. The role and practice of the genetic nurse: report of the AGNC working party. J. Med. Genet. 34, (1997)
141-147.

[12] Skirton, H., Barnes, C., Guilbert, P. et al. Recommendations for education and training of genetic nurses and counsellors in the United Kingdom. J. Med. Genet. 35, (1998) 410-412.

[13] Stemerding, D., Koch, L. and Bourret, P. DNA diagnosis and the emergence of cancer genetic services in European health care. Eur. J. Hum. Genet. 5(Suppl 2), (1997) 25-30.

[14] Wooster, R., Bignell, G., Lancaster, J. et al. Identification of the breast cancer susceptibility gene BRCA2. Nature 378, (1995) 789-792. 


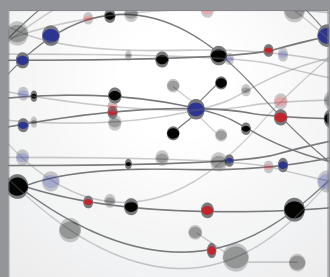

The Scientific World Journal
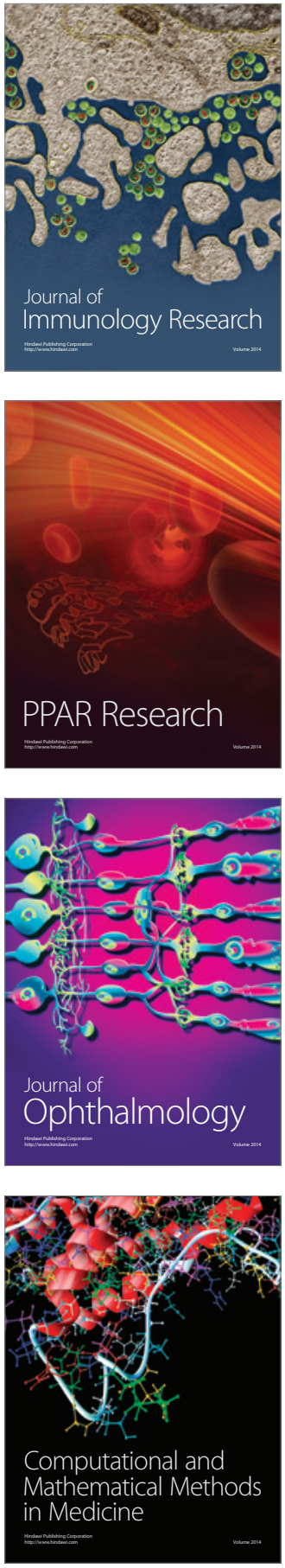

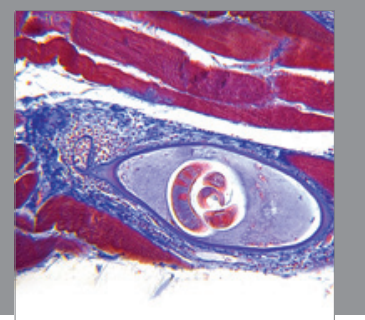

Gastroenterology

Research and Practice
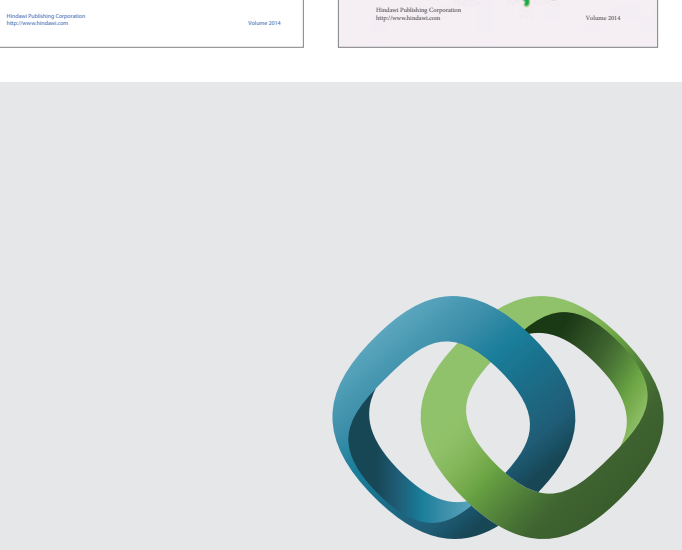

\section{Hindawi}

Submit your manuscripts at

http://www.hindawi.com
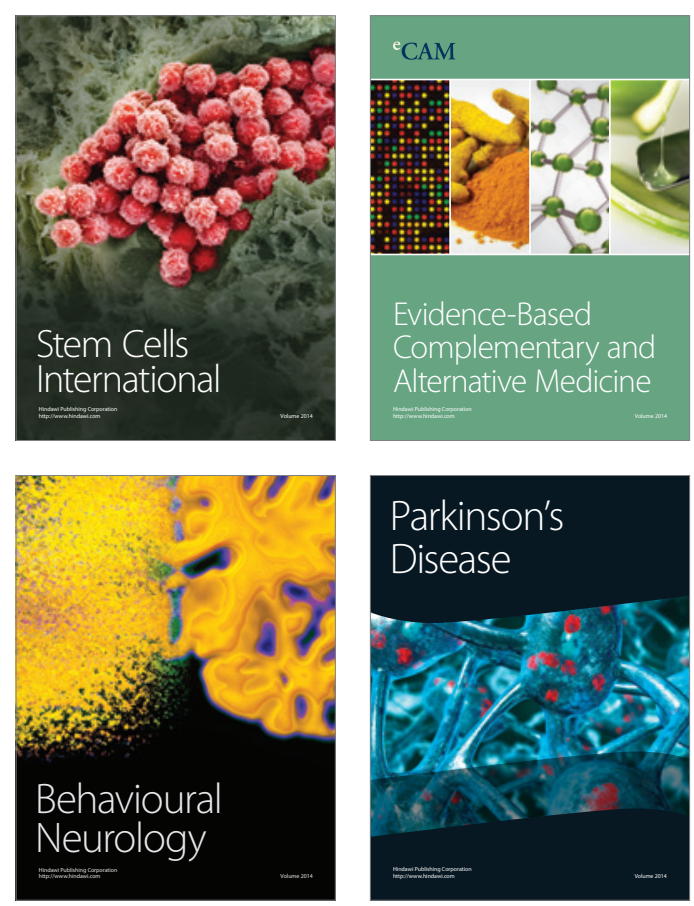

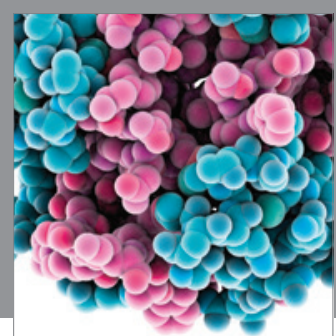

Journal of
Diabetes Research

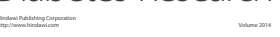

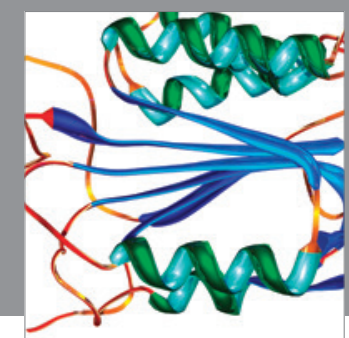

Disease Markers
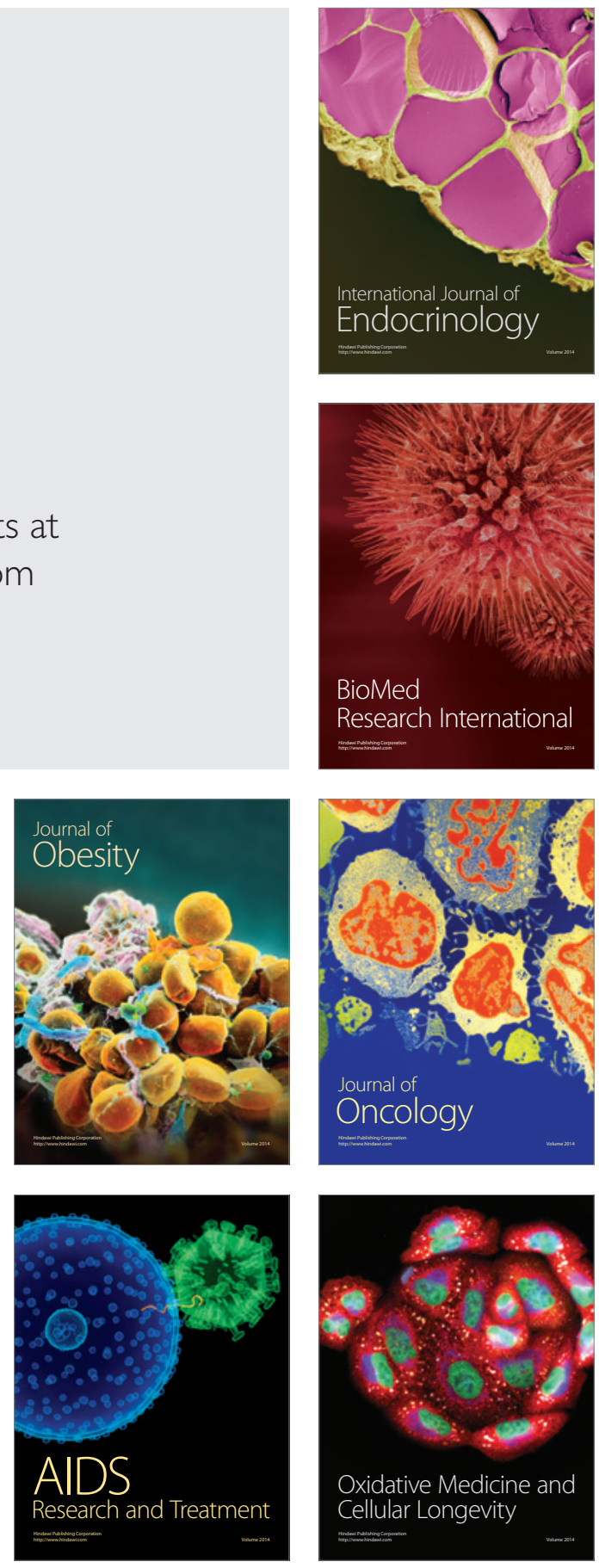